\title{
A IDÉIA DA SOBERANIA DO POVO NA LITERATURA DO FIM DA IDADE MÉDIA
}

A época mais interessante da história cristã e um dos períodos mais ricos e fecundos para os prosadores do século $\mathbf{X X}$ é o fim da Idade Média, por cujo cadinho espiritual e revolucionário passaram idéias antigas e vitoriosas que foram consumidas e purificadas para que surgissem concepções novas e audaciosas. Pode-se dizer que os séculos XIV e XV são o cemitério do espírito medieval e o berço do espírito da Idade Moderna.

Se é lícito reduzir a esquemas a história do espírito ou dar um leito de Procusto à vida rica e fluente de uma época histórica, devemos mencionar, como característica do fim da Idade Média, o particularismo que marca, também, a Idade Moderna. Ao contrário do universalismo da alta Idade Média, na qual o universal se afirmava nos juízos dos indivíduos e dos povos contra o particular, o nacional, o individual, - no fim da Idade Média acorda, na vida política, a consciência nacional que, vencendo as tendências universalistas do Papado e dos imperadores, forma os estados independentes autônomos nacionais. Por outro lado, na vida da sociedade, as funções das comunidades orgânicas que realizavam admirável coesão social sofrem a pressão do sempre crescente pêso social dos indivíduos que levaram uma como vida monástica e cuja consciência foi, então, despertada. O método do pensamento do homem da alta Idade Média caracterizava-se pelo objetivismo, porque sua concepção do mundo, sua fé e suas convicções morais eram dirigidas' peló ensinamento da Igreja expresso nos dogmas e nas normas morais; no fim da Idade Média, porém, aparece o subjetivismo, característico também, da renascença, do iluminismo e da Idade Moderna em geral, que deu a medida da verdade e determinou as convicções subjetivas e as opiniōes individuais. Concomitante sociológica dessa mudança espiritual foi a laicização da sociedade medieval clerical, porque crescia sempre ó número de pensadores leigos entre os construtores e portadores da cultura, que não eram tão limitados pela disciplina eclesiéstica como foram os clérigos. A consequêencia natural do particularismo, do subjetivismo e do laicismo, assim na filosofia do Estado como na prática política, ao contrário do princípio autoritário e da forma hierárquica e monárquica do govêrno da alta Idade Média, foi, no fim desta, dar sempre mais impor- 
tância ao método de pensamento democrático, que queria construir - Estado e a sociedade modernos, segundo as exigências da idéia de soberania do povo. Embora continui, ainda hoje, aberta a questão sôbre se as idéias filosóficas dirigem a evolução política e preparam as mudanças sociológicas ou se a filosofia apenas reconhece e exprime as novas tendências da evolução política e sociológica, podemos afirmar, corajosamente, que as idéias sociais líderes de uma época conhecê-mo-las mais fielmente através da literatura política e filosófica do Estado.

$*$

Quando procuramos, na literatura política do fim da Idade Média, a idéia de soberania do povo sôbre a qual está construída a Idade Moderna, dirigimos logo nossa atenção para o autor mais representativo da concepção política do fim da Idade Média. Talvez exagerem os historiadores e comentadores a importância filosófica e o alcence espiritual de Marcílio de Pádua e de sua grande obra Defensor Pacis, quando chamam a êsse inovador verdadeiramente audacioso para sua época o pai da política moderna (Battaglia), o autor intelectual da revolução francesa (Pastor), o precursor de Lutero (Laurent e Hollweck), o arauto de um múndo nascente e o profeta de uma nova ordem social (Emerton), o mestre de Maquiavel (Benoist), o criador daquele radicalismo político, cujos representantes mais expressivos foram Althusius e Rousseau (Atger), ou quando comparam êsse "célebre herético" e "famoso cismático" que destruiu a catedral da ciência medieval, com Heróstrato que incendiou o templo de Diana, em Efeso. Apesar de exageradas tais afirmações, não podemos negar que, ao lado do "Diálogo" de Guilherme de Occam, que melhor representou a idéia da soberania do povo na eclesiologia, foi Marcílio de Pádua quem, na filosofia do Estado e na literatura política do fim da Idade Média, resumiu e exprimiu mais claramente $o$. conteúdo e o programa político da idéia de soberania do povo que, nascida na Idade Antiga como pensamento político, continuou a existir, também, durante a Idade Média.

A filosofia e a vida, a ciência do Estado e política prática estão em mútua e constante influência e por isso, não é de admirar que o pretenso panfleto político de Marcílio de Pádua que traz, no fundo, tôdas as características de uma filosofia de Estado, tenha inspirado e influenciado muito os grandes acontecimentos históricos de sua época, como a "Apelação de Sachsenhausen" (1324) na qual foi expressa, pela primeira vez, a idéia do conciliarismo, a "Declaração de Renze" (1328). Nesta exprimiu-se também' a so- 
berania do estado alemão nacional contra o universalismo do $\mathrm{Pa}$ pado medieval, e especialmente o caso de Luiz da Bavária (1328), que foi a primeira afirmação de eleição democrática de um imperador, inspirada pela idéia da soberania do povo. A história do espírito humano ensina que as grandes idéias formadoras das épocas históricas não aparecem, inesperadamente, como deus ex machina, no pensamento das gerações que se sucedem, mas se formam e amadurecem longamente nos movimentos da história até que recebam uma expressão definitiva por um pensador mais sintético que intuitivo. Se quisermos, pois, julgar com justiça a posição de Marcílio de Pádua na literatura política do fim da Idade Média, consoante a teoria sociológica da soberania do povo, devemos conceder-lhe a importância que, nos tempos modernos, atribuimos a Rousseau, como se ambos ocupassem os dois focos da mesma elipse.

A idéia da soberania do povo que na formulação revolucionária de Rousseau significa que a fonte última e o verdadeiro proprietário do poder estatal é o povo, não foi desconhecida do pensamento da Idade Média, já porque ao entrar em contato com o direito romano, recebeu novo impulso para afirmar-se mais; já porque achou sua realização política na praxe das cidades-estados italianas; já, finalmente, porque encontrou melhor ressonância na opinião pública francesa, que se tornou sempre mais leiga e democrática.

Como as outras grandes idéias do espírito humano, a idéia de soberania do povo parece-se com os rios de montanha, cujos cursos, em grande parte subterrâneos, invisíveis e silenciosos, só se deixam ver, em plena luz, quando já densos e caudalosos, desembocam violentos nas planícies. Marcílio de Pádua sustenta que a essêncıa da soberania é o poder legislativo, populus, id est, universitas civium superiore carens. Mas se observamos a formação e a evolução do direito romano, podemos notar que, conseqüentemente, o povo romano era o fundamento do poder legislativo, mesmo quando renunciou ao exercício do poder legislativo em benefício do imperador. Talvez não exista frase mais citada do Digesto, obra escrita por ordem de Justiniano, coletânea das sentenças dos juristas do império romano dos séculos II e III, do que a afirmação de Ulpianus: quod principi placuit, legis habet vigorem (Dig. I, $4,1)$. Esquecemos porém de que, explicando seu pensamento, acrescenta êle: utpote cum lege regia, quae de imperio lata est, populus ei et in eum omne suum imperium et potestatem conterat. Este paradoxo que dá ao pessoal e ilimitado poder legislativo do imperador um fundament democrático mostra que, mesmo nos séculos florescentes de absolutismo inapelável, isto é, de 
Juliano a Justiniano, os juristas romanos conservavam, embora de maneira velada para os olhos leigos, a doutrina vinda de Cícero pela qual o povo é a fonte última do poder legislativo. O próprio Justiniano para quem o povo, nem como legislador direto nem como autor do direito consuetudinário, pode exercer seu poder legislativo a que renunciou em favor do imperador, reconhece que o poder legislativo dêste deriva do povo: cum enim lege antiqua quae rege nuncupabatur, omnis ius omnisque potestas populi Romani in imperatorium tranlata sun potestatem. (Cod. 1, 17, 1, 7). Assim, nas estreitas veias subterrâneas continua a existir, ao longo dos séculos, a idéia de soberania do povo.

$\mathrm{Na}$ aurora da renascença, isto é, na renovação dos antigos valores romanos culturais, começou a restauração vitoriosa do direito romano pelo fim do século XI nas escolas de direito romano fundadas em Roma, Ravena, Pádua e Bolonha. A Faculdade de Direito Romano, de Bolonha, tornou-se a mais célebre universidade da Idade Média. Nela ensinaram, nos séculos XI e XII, famosos juristas, como Irnerius, Bulgarus, Azo e Hugolinus que glosando as Pandecta e as Digesta, fecundavam o direito conônico com os pontos de vista do direito romano. Seus comentários às doutrinas de Caius, Pomponius, Ulpianus e dos demais grandes juristas romanos continham, pela primeira vez, na Idade Média, a formulação, em têrmos claros, da idéia de soberania do povo. Louvando-nos em Carlyle em sua obra fundamental sôbre a evolução da ciência politica medieval intitulada $A$ history of mediaeval political theory in the West, afirmamos que a doutrina de Caius e Ulpianus, da igualdade e liberdade da natureza humana e dos direitos dos cidadãos que intervêm na direção da vida do Estado, se inspirou na obra de Cícero De legibus, doutrina que foi o fundamento filosófico da sua teoria de que todo poder legislativo e político ceriva do povo.

Mas Carlyle vai além e afirma que essa teoria é, pelo menos, uma das fontes de onde deriva a doutrina do contrato social de Rousseau, que estaria assim, na sua forma primitiva e elementar, em Caius e Ulpianus. Para mostrar em que grau foi inspirada a legislação justiniana na opinião de que o povo romano é o fundamento de todo o direito, basta citar a explicação de Caius, ao afirmar que o povo, o populus, é o único que tem o direito de constituir leis: Lex est, quod populus iubet atque constituit e ajuntía que todo poder legislativo deriva dệle. Assim, o plebiscito que é feito ùnicamente pela plebs, sem a colaboração das demais classes sociais, tem a fôrça de lei, porque tal o foi determinado pela $L e x$ Hortensia. As prescrições constitucionais dos regentes em forma ou de decretos ou de éditos ou de rescritos tinham o caráter de lei porque os imperadores, por lei, receberam do povo o seu poder. Também os magistrados, especialmente o pretor, têm o poder de fazer éditos durante o seu mandato; mas não resta dúvida sôbre 
que só estão investidos de semelhante poder, em virtude de sua eleição pelo povo. A responsa prudentium, isto é, doutrina e os juízos dos juristas possuem fôrça de lei, porque também êles receberam do povo licença para fazê-las. A única forma de lei, cujo caráter de lei permanece indeciso, são as decisões senatoriais, - senatus consultum - porque nem Caius, nem o seu contemporâneo Pomponius, - que explica, em têrmos claros, a evolução do direito romano, de Rômulo às instituições jurídicas da época imperial, não podem reduzí-las com argumentos irretorquíveis, ao único fundamento da legislação que é o povo. Os juristas romanos poréin esclarecem que o poder do senado não podia deixar de reduzir-se exclusivamente ao povo o qual, não podendo reunir-se em sua maior parte, elegia cem senadores, aos quais conferia o poder de deliberar em seu nome.

Os grandes juristas medievais pregavam a idéia da soberania do povo manifestada na legislação mais clara e decididamente do que os juristas das Digesta. Assim é que Irnerius, Bulgarus e Placentinus ensinavam não sòmente que $\circ$ povo, populus, universitas e não o indivíduo tem o poder de fazer, interpretar e esciarecer as leis, mas deram um passo adiante, porque quando usavam expressões como estas: vicem obtinet universitatis magistratus, imperator vicarius populi de envolta com a idéia de soberania do povo, sugeriam a da representação do mesmo povo. De acôrdo, pois, com êsses antecedentes, devemos atender ao fato de Marcílio de Pádua estar bem no foco da evolução medieval da idéia de soberania do povo, porque no capítulo XI do Defensor pacis não pôs em dúvida mais convincentemente a capacidade do indivíauo de fazer leis do que Irnerius ou Bulgarus, e na tese mais citada do capítulo XII - o mais famoso de sua obra - não ultrapassa o ensinamento dos juristas romanos na questão da soberania do povo e da sua representação. Nos autem dicamus secundum veritatem atque consilium Aristotelis legislatorem, seu causam legis effectivam et propriam esse populum seu civium universitatem, aut eius valenciorem partem, per suam electionem seu voluntatem civium in generali civium congregatione per sermonem expressam. Embora na formulação de sua tese Marcílio se refira a Aristóteles, apesar de não ser um jurista ex officio que não só não citava mas ainda talvez nem conhecia os cientistas famosos da época justiniana ou seus intérpretes medievais, os mais entusiastas admiradores do doutor paduano devem reconhecer que êle apareceu no céu do pensamento medieval, não como um deux ex machina, como uma inteligência criadora, espécie de súbito e inesperado meteoro para ditar, de primeira mão, a idéia da soberania do povo, formadora da mentalidade política moderna. Tal concepção, aliás, não estava muito longe do pensamento cristão medieval o qual foi sempre contrário à idéia do poder totalitário e ilimitado. Santo Tomaz de Aquino, o mais autêntico intérprete do pensamento me- 
dieval, vê no poder o órgão servidor do bem comum e salienta a importância do papel do povo no govêrno.

Não devemos, porém, esquecer de que Marcílio era paduano e de que Pádua como muitas outras famosas cidades italianas, entre as quais Florença, Pisa, Gênova, foi uma república, de modo que na sua cidade natal, nos anos mais decisivos de sua juventude, quase com o leite materno, podia respirar o pensamento democrátiço e estudar a constituição de uma cidade-estado fundada sôbre a idéia da soberania do povo. O espírito democrático pertencia às tradições de Pádua porque, segundo Muratori, os paduanos, desde os tempos romanos furono fedelissimi alla Repubblica Romana, e nemici della novità di Cesare. A estranha Patavinità e o especial gôsto paduano que, para Muratori, os romanos e sobretudo Asinius Pollio descobriram no grande historiador Titus Livius, foi, ao lado de uma expressão do seu dialeto, uma adesão calorosa às instituições republicanas. Que êsse espírito democrático da época de Marcílio não desapareceu entre os paduanos é, prova evidente e irrecusável, o fato de em 1300, quando Bonifácio VIII, por ocasião do gran Giubileo, celebrara em Roma festas de caráter universal para fazer sentir o poder e o pêso mundial da sovranità papale. Por êsse mesmo tempo, os cidadãos paduanos organizaram também esplêndidas e espetaculares festas para celebrar a idéia da sovranità popolare, propter Paduae maximan libertatem. Essa sovranità popolare, aliás, foi contrária à sovranità imperiale e, por isso, é muito compreensível que, por ocasião da morte de Henrique VII, que havia sido tão calorosamente saudado por Dante, grande admirador medieval do imperialismo cesareano, tinham sido novamente organizadas, em Pádua, magníficas festas, com congressos populares, procissões e iluminações.

A constituição de Pádua foi, também, inspirada pelo espírito democrático e republicano. Com efeito, na época de Marcílio, o poder governamental estava nas mãos de três conselhos. O Consiglio degli Anziani, com 18 membros eleitos entre os cidadãos melhor formados e mais experientes; o Consiglio Minore com 40 e, mais tarde, 60 membros, dos quais uma parte era nobre e outra plebeia; o Consiglio Maggiore, a princípio com 300, depois com $600 \mathrm{e}$, finalmente, 1.000 membros. Todos os cidadãos eram membros do Comune; mas êste reunia-se muito raramente, só na ocasião de grande perigo para a Pátria. As reuniōes dos diversos conselhos realizavam-se na Sala della Ragǵione, cujo nome já indicava que, no govêrno da cidade, o primado deve repousar, não na autoridade, mas na razão e no espírito. O princípio aplicado, por ocasião da eleição dos membros dos conselhos, foi, como sempre Marcílio salientou na sua obra, o de eleger os cidadãos mais capazes, - valenciorem civium partem -, princípio que era a garantia de não enveredar a república por um caminho cego. Para vermos que importância assumia aos olhos de Marcílio a consti- 
tuição de Pádua, sua cidade natal, é bastante citar o seu pensamento dirigido não sòmente para o Comune da universitas civium, - parlamento da universitas civium valencior pars, mas ainda para as duas outras organizações que fazem parte, em nome do povo, do exercício da soberania, isto é, as da legislação, numa comunidade que prepara e noutra que aprova as leis.

No começo de 1300, Marcílio de Pádua deixou esta cidade transferindo as suas atividades para París, então centro da vida política e científica européia. Na vida espiritual fermentada e revolucionária e na opinião pública sempre mais laicizada e democratizada de París, se bem que ainda em estado plasmático, mas dando já margem a uma síntese de planos, visões e pensamentos, pôde Marcílio de Pádua elaborar, no nível de sua época, o ideal da soberania do povo, como caminho da solução da crise política. Por êsse tempo, havia justamente terminado a grande luta espiritual levada a efeito pelos teólogos e juristas da côrte de Filipe, - Belo, contra os curialistas de Bonifácio VIII, na defesa do reino independente nacional e do poder independente real. Nesta luta, os realistas franceses já achavam na idéia da soberania do povo os limites necessários contra as tendências da plenitudo potestatis papal. A fórmula que, então, se tornou famosa deriva de João de París: populo faciente, et Deo inspirante, onde não injustamente pensam alguns descobrir a outra fórmula moderna "da graça de Deus e da vontade do povo". Quando João de París fala da coroação de Carlos Magno explica que esta non fuit factum per solum Papam, sed populo acclamente et faciente, cuitus est subicere cui vult sine alterius praeiudicio... nam populus facit regem et exercitus imperatorem. E se João de París não representa a idéia de soberania do povo, como está em Rousseau, porque, algumas vêzes, no sentido tomista, a atribui indiretamente a Deus, e em outras, diretamente. Entretanto é êle quem exprime a idéia de soberania do povo no terreno da eclesiologia com estas conhecidas palavras: concilium est supra papam. Depois, a idéia do conciliarismo com a ajuda de João de París e de Occam recebeu asilo na Universidade de París que foi chamada o terceiro poder daquele tempo e que, segundo a fina observação de Dempf, ficou a serviço dêsse espírito laicista e democrático porque queria sufragar e dar um papel a Bilduggsaristokratie junto à aristocracia da ordem e da hierarquia, na direção da vida da Igreja. Não podemos esquecer que a audaz e renovadora aspiração de Marcílio, que foi Magister e depois, Rector da Universidade de Paris, desabrocha nas suas grandes linhas, na segunda e maior parte do Defensor pacis, que trata exclusivamente da Igreja, onde valoriza a idéia de soberania do povo nas exigências do conciliarismo.

Porém, Marcílio, em París, viu não sòmente as lutas eclésiopolíticas, mas também aquelas lutas que a respeito da política interna produziam o poder real central e observou ainda a oposição 
dos nobres e burgueses contra a política centralizante, financeira e exploradora de Filipe, o Belo, e seus sucessores. Naturalmente, êle, que era filho de uma cidade-estado italiana democrática, estava também na França ao lado da oposição popular contra o absolutismo real. Certamente devia conhecer a atmosfera quase revolucionária que inspirou, no início do século XIV, o pensamento da opinião pública e da sociedade leiga francesa, que foi expresso, aliás, no poema alegórico Roman de la Rose. Essa obra que é uma mistura de alegoria pura, da descrição poética e de uma filosofia séria e frívola, descreve quase, com a pena e o entusiasmo de Rousseau, o antigo estado paradisíaco, no qual os homens viveram em absoluta liberdade, numa igualdade plena, sem medo nem luta. Esse mundo de paz e de caridade foi invadido pela malícia, mãe de todo o domínio, sem a qual o homem nunca seria rei nem juiz. A malícia descobriu a concepção dos valores, a propriedade particular, libertou as paixões más e, conseqüentemente, a sociedade sentiu a necessidade de organizar-se na defesa dos fracos e da propriedade contra os fortes. Elegeram, pois, em conselho, o mais forte, que jurou defender o direito e cuidar da existência e segurança da comunidade. A idéia da soberania do povo está bem expressa naquele momento, em que a autorização dada à pessoa eleita the era retirada pelo povo. Essa obra, escrita com paixão, em belo estilo e lingua secular, defendia a igualdade natural dos homens, explicando que a liberdade ingênita e o intelecto dado por Deus aos homens é o seu único título verdadeiro de nobreza e que a sua cultura vale mais que tôda ordem real, oficial ou cavalheiresca. Nada revela melhor do que essa obra como, no início do século XIV, foi invadido o pensamento cuitural da opinião pública francesa leiga, pela idéia do individualismo exagerado e da soberania do povo, no sentido de Rousseau, fundada no contrato social, em comparação com a qual as teorias do Defensor pacis de Marcílio aparecem como de natureza conservadora, por seguir as pegadas de Aristóteles, para o qual, no sentido da escolástica, a origem do Estado se origina do direito natural e aceita a instituição orgânica do Estado medieval sôbre as corporações.

Para vermos, em sua luz reta e numa perspectiva adequada, a significação de Marcílio de Pádua na história do espírito, devemos comparar a sua teoria sôbre a evolução da idéia de soberania do povo - servindo-nos ainda da imagem da elipse - como o foco moderno da teoria de Rousseau. Dessa comparação evidencia-se que Marcílio ainda não é tão revolucionário e individualista, quanto sua teoria está constituida em bases aristotélico-escolásticas e por quantos laços se prende ao ideal do Estado medieval orgânico. 
A diferença mais fundamental que separa Marcílio de Rousseau é que aquêle não ccnstrói o iđeal de soberania popular sôbre um contrato social. Ao passo que Rousseau descansa todo o pêso c.e sua tecria no contrato social, Marcílio - ao contrário do que pensa Scholz, o mais célebre intérprete do nosso autor, para quem - Paduano apenas menciona a doutrina do contrato social, - ignora totalmente semelhante teoria, pois, seguindo as tradições da filosofia escolástica, baseada em Aristóteles, deduz a faculdade legislativa dos cidadãos e o poder legislativo do Estado, da natureza social do homem. Com efeito, segundo êle, o homem é impelido, como por instinto inato, pela própria inclinação natural a reunirse em comunidade e assim, por uma evolução orgânica se forma, primeiro a comunidade familiar, depois a citadina e, finalmente, a comunidade estatal autárquica. Portanto, o Estado como organismo vivo, não é obra nem da vontade nem da decisão humana. $\mathrm{E}$ no capítulo XIII, onde pretende êle basear filosoficamente o poder e a soberania da universitas civium, retorna às explicações de Aristóteles sôbre a origem do Estado: Natura quidem igitur in omnibus impetus est ad talem communitatem. E se o homem tem, por natureza, tal instinto, não the pode faltar nem a capacidade nem a vontade para fazer boas leis sem as quais não pode associar-se a uma comunidade estatal.

Mas não se pode negar que encontramos em Marcílio um texto dando a entender que, segundo êle, o Estado seria o resultado do livre arbítrio do homem quase confundindo a teoria da evolução natural do Estado com a teoria do contrato social: Convenerunt enim homines ad civilem communicationem propter commodum et vide sufficienciam consequendam et opposita declinandum. (D.P. D.I. cap. XII. § 7.) Esse texto, todavia, deriva também de Aristóteles, que, na tradução de Moerbeke, assim está formulado: Conveniun autem et ad vivere gratia ipsius et continet politicam communionem. ( Pol. III. 4, 3). Contràriamente ao que pensam Gierke e Atger, que vêem na frase de Marcílio uma alusão ao contrato social, ela não significa senão que o Paduano, nas Iinhas de Aristóteles e da filosofia escolástica na questão da origem do Estado, põe junto à inclinação natural do homem a sua atividade intelectual consciente. Aliás, não sòmente Suarez e a escolástica da Renascença mas também a própria escolástica medieval reconheciam que, apesar de o homem ser impelido à vida comunitária e estatal por uma insuficiência natural, verifica com o seu intelecto essa necessidade ontológica e, por isso, a exigência da comunidade e do estado é um ato eminentemente intelectual selado por uma decisão do livre arbitrio. Levado embora o homem à fundação da família por um instinto sexual natural, esta permanece, entretanto, um ato humano intelectual e livre, porque realiza um acôrdo humano e um contrato para a vida. Também, segundo Santo Tomaz, o caráter moral do Estado pelo qual êle se distingue das de- 
mais comunidades naturais meramente instintivas, é dado pela colaboração do intelecto humano e da vontade livre: ratio constituens civitatem.

Essas cotısiderações servem para acentuar e iluminar vivamente a primeira distinção fundamental entre as teorias de Rousseau e de Marcílio, uma vez que êste está mais perto das teorias escolásticas do que da doutrina da soberania do povo, de Rousseau, quando ensina que a comunidade do povo é o primeiro proprietário e não criador da soberania que tem suas raízes na legislação. Marcílio, porém, não é lógico quando, de uma teoria fundamentalmente escolástica com a qual concorda em substância, tira conclusões idênticas às de Rousseau, ensinando que o povo, apesar de haver investido alguém ou uma comunidade do poder de legislar, pode limitar tal poder, no seu conteúdo e na sua duração, e até retirá-lo, porque o legislador eleito não é legislator simpliciter, mas sòmente representante do primus legislator, isto é, do povo, da comunidade dos cidadãos.

A primeira diferença fundamental, portanto, entre Marcílio e Rousseau é que Marcílio, apenas confessando a soberania total e inapelável da comunidade do povo, manifestada na legislação, não é individualista porque, para basear sua teoria, não parte da igualdade humanz do estado natural antigo nem da liberdade individual dos cidadãos. De acôrdo ainda com o pensamento orgânico da Idade Média, êle vê como os mais pequenos componentes políticos da sociedade e do estado, não os indivíduos independentes e livres, mas as corporações, as partes, os officia. Devemos, pois, considerar Marcílio como um representante da democracia moderada, limitada, qualitativa, e, para usar da expressão atualmente tão abusada, burguesa. Rousseau, neste caso, representaria a democracia quantitativa popular. E nesse sentido, Marcílio é novamente filho de seu tempo e discípulo de Aristóteles que, ao escrever a "Política", tinha diante de si as cidades-estados gregas, protótipos das cidades-estados italianas medievais, por isso que, na vida política, Marcílio reconhece sòmente a participação de classes privilegiadas dos cidadãos e nunca de todos os cidadãos. E no sentido do ideal da democracia e da soberania do povo exprime, apenas, que o poder legislativo está no povo, na comunidade dos cidadãos: Civem autem dico secundum Aristotelem eum, qui participat in communitate civili, principatu aut consiliativo vel iudicativo secundum gradum suum. Este secundum gradum suum ultrapassa as restrições de Aristóteles porque, não sòmente com o Estagirita exclui do exercício do poder político, as crianças, as mulheres, os estrangeiros, os escravos, e qualifica de cidadãos ùnicamente os participantes do poder judicial e executivo senão também distingue mesmo entre os cidadãos ativos capazes de votar, segundo as diversas classes sociais a que pertencem. Não se pode negar que essas afirmações de Marćlío foram inspiradas pela organização po- 
lítica das cidades-estados italianas, onde a liberdade política foi privilégio das classes burguesas mais favorecidas, como exprimiu Battaglia: il popolo, in cui risiede la sovranità, è il partito dom to' nante, $e$ in esso la parte veramente attiva è rappresentata da pochi.

Partindo dessas considerações devemos mostrar a diferença mais fundamental entre as teorias democráticas de Marcílio e de Rousseau. Marcílio defende fielmente a democracia indireta ou parlamentar; Rousseau prega uma democracia direta, popular. E no seu idealismo radical sustenta até a impossibilidade do exercício da vnntade do povo, mediante os representantes eleitos; ao passo que o muito prático e medievalíssimo Marcílio é o paladino e o mais convencido pregador do regime parlamentar. Sua tese mais citada e disputada, onde confessa sua fé no regime parlamentar, pode encontrar-se na $1 . a$ dictio, cap. XII, $\S 3$, de sua famosa obra: Nos autem dicamus secudum veritatem atque consitium Aristotelis legislatorem, seu causam legis effectivam, ptimam et propriam esse populum, seu civium universitatem aut eius valen ciorem partem. De suas explicações ulteriores fica patente que èle queria limitar ao mínimo as reuniões da civium universitas pondo com tôda a diligência em primeiro lugar, o munus da pars valencior, representante da civium universitas. Durante muito tempo, entretanto, foi questão disputada se a valencior pats devia ser tomada em sentido quantitativo ou qualitativo, isto é, se nela devíamos procurar o parlamentarismo no sentido moderno fundado na maioria numérica ou a aristocracia do nascimento ou de cultura, segundo a hierarquia das corporações, vigente na Idade Média. Recentemente, porém, as magníficas edições críticas de Prévité-Orton e Scholz, que restauraram o texto original, - valenciorem inquam partem, considerata quantitate personarum et qualitate in communitate - autorizam-nos a afirmar que as duas alternativas que pretendem interpretar o pensamento de Marcílio devem, de certa maneira, ser conciliadas entre si. Para isso vamos recorrer a uma analogia. Marcílio valoriza o princípio da soberania do povo não sòmente na filosofia do Estado, mas também na eclesiologia. Como na vida do Estado a fonte do poder público e da lei é a universitas civium, assim a universitas fidelium representada pelo concílio ecumênico é a fonte do poder eclesiástico na questão da fé e da disciplina. O concílio ecumênico, porém, isto é, a valencior pars fidelium unifica, admiràvelmente, na Igreja, o princípio qualitativo e quantitativo na sua composição. Teòricamente, o concílio ecumênico devera ser a assembléia de todos os fiéis; mas como êstes se encontram dispersos pelo mundo inteiro, sòmente poucos podem representá-los na sua totalidade. Eis porque Marcílio aconselha que tôdas as dioceses do mundo, segundo sua importância, e respeitando o valor quantitativo e qualitativo dos fiéis, - secundum ipsarum proporcionem in quantitate et qua- 
litate personarum - elejam representantes, principalmente sacerdotes, mas leigos também, que, por sua vida privada íntegra e por seu conhecimento das leis divinas, sejam capazes de, autorizados pela comunidade, decidir em questões de fé, de moral, de culto, e de disciplina.

Na composição do concílio ecumênico podemos achar uma analogia na maneira como Marcílio imaginava a harmonização do princípio qualitativo e quantitativo na convocação do pariamento que representa a vontade dos cidadãos. Por essa analogia, os representantes capazes de fazer as leis devem ser escolhidos de acôrdo $\mathrm{com}$ as províncias, sua grandeza e significação e segundo o número e autoridade dos súditos. O princípio qualitativo, portanto, deve ser determinado ou afirmado na elegibilidade dos súditos, para o qú deveria ser usado o critério da integridade moral e da competência. Marcílio, porém, não quer sòmente, por assim dizer, uma democracia qualitativa, mas vê bem claramente aquelas diferenças, que não parecem notadas pelo racionalista Rousseau, isto é, o que as circunstâncias políticas, sociológicas, saciais e morais dos diversos países e povos significam para a construção das suas respectivas democracias, uma vez que não explica as minúcias relativas ao modo da eleição, deixando sua determinação a cargo das situaçôes e costumes especiais de cada país.

Existem, na verdade, concordâncias surpreendentes entre Marcílio e Rousseau na questão da soberania popular. Assim, ambos sustentam a vontade do povo como soberana e inalienável; ambos vêem o conteúdo exclusivo da soberania na legislação; ambos, quase ipsis verbis e da mesma maneira, explicam que o direito da legislação emana do povo e que são mais observadas as leis por êste feitas; ambos separam, no espírito da democracia pura, o poder legislativo do executivo e entregam êste a um órgão dependente do povo chamado pars principans (Marcilio) ou gouvernement (Rousseáu). Nem por isso, entretanto, deixa de ser longo o caminho de Marcílio a Rousseau, quase tão longo como o que vai do início do século XIV ao fim do século XVIII.

$O$ espírito e indivíduo humano deveriam desvencilhar-se de tôdas as corporações de caráter civil e religioso; a sociedade deveria, em grande escala, diferenciar-se e atomizar-se para que a autonomia do intelecto humano, a igualdade da natureza humana, a individualidade da pessoa humana pudessem receber uma formulação sociológica e filosófica na doutrina da soberania do povo de Rousseau. Seria interessante seguir o caminho dessa evclução porque, então, poderíamos observar que já em Marcílio, e mais adiante, no fim do século XIV e nos séculos XV e XVI, principalmente na doutrina da constituição eclesiástica, no conciliarismo, na democracia do protestantismo, a idéia da soberania do povo mostrou a sua influência e que sòmente mais 
tarde, os puritanos que representavam o pensamento de Calvino é que vieram a realizá-la na vida do Estado.

$\mathrm{Na}$ passagem da Idade Média para a Idade Moderna tendose deslocado o centro da vida comunitária do seio da Igreja para - Estado, não é de admirar que a mais forte exigência da liberdade política e da democracia estatal seja uma conseqüencia da vitória da idéia da soberania do povo encarnada no protestantismo. O precursor imediato de Rousseau, como representante da idéia de soberania do povo, nascido do individualismo exagerado, foi Locke, cujas idéias políticas derivavam, em sua maioria, da obra "Laws of ecclesiastical policy" da autoria de Hooker, teólogo protestante inglês do século XVI, que representou a concepção do mundo e da vida protestante e puritana. A nosso ver, a significação de Marcílio de Pádua, na história do espírito humano, está naquele momento em que valorizou, clara e agudamente, a idéia de soberania do povo defendendo o conciliarismo exigindo, mais fortemente que Wiclif e Hus, a introdução da democracia na vida eclesiástica. Dando a conhecer o pensamento da filosofia do estado do Doutor Paduano pretendíamos salientar-lhe a contribuição original, na evolução da idéia de soberania do povo, pelo que, mencionamos os aspectos em que seu pensamento é tributário da época em que viveu e pelos quais se distancia da hoje clássica doutrina de Rousseau. E, como num instantâneo, desejaríamos eternizar o estado da evolução da idéia de soberania do povo no início do século XIV, tão bem representada no tratado de Marcílio, porque estamos convencidos de que os grandes pensamentos que dirigem a história do espírito e da vida da humanidade, - entre os quais figura também a idéia de soberania do povo - não são obra de um só homem, por mais genial que êle seja, mas fruto coletivo de pensamento de muitas gerações e de longos séculos.

\author{
Pe. NICOLAU BOER \\ Da Pontificia Universidade \\ Católica de Sāo Paulo.
}

